\title{
The Influence of Political Regime on State-Level Disciplinary Actions of CPAs Sanctioned by the PCAOB
}

\author{
Abdullah Al-Moshaigeh ${ }^{1}$ - Denise Dickins ${ }^{2}$ (D) . Julia L. Higgs ${ }^{1}$ \\ Received: 9 July 2020 / Accepted: 31 December 2020 / Published online: 19 January 2021 \\ (c) The Author(s), under exclusive licence to Springer Nature B.V. part of Springer Nature 2021
}

\begin{abstract}
We investigate whether enforcement is influenced by politics by comparing the severity of PCAOB sanctions of individual CPAs to the severity of related state-level disciplinary actions imposed by boards of accountancy (BOAs). Our results provide evidence that when responding to PCAOB sanctions, BOAs under Republican regimes impose less severe penalties than do BOAs under Democratic regimes. Our data and analyses inform the regulatory and enforcement practices of the accounting profession and other professions. Most directly, motivated by improvements in technology that facilitate the cross-jurisdiction practice of public accounting, states have adopted mobility laws where CPAs are only required to be licensed in their state of residence to practice in multiple states. These laws simplify licensing but may complicate enforcement. Beyond generalized red-state, blue-state differences in enforcement, we find that non-resident CPAs receive less severe disciplinary actions. If not reasonably consistent across BOAs, regulators may be unwilling to delegate responsibility for enforcement to another state's BOA.
\end{abstract}

Keywords Board of Accountancy $\cdot$ PCAOB $\cdot$ Sanctions $\cdot$ Enforcement $\cdot$ CPA

\section{Introduction}

In the US, certified public accountants (CPAs) are obligated to follow many rules and regulations including those of State Boards of Accountancy (BOAs-all CPAs), the American Institute of Certified Public Accountants (AICPA-member CPAs), and, if engaged as an auditor of a US publicly traded company (issuer), those of the Public Company Accounting Oversight Board (PCAOB) and Securities and Exchange Commission (SEC). Regulation of professionals is an important role of the states and consistency in regulation and enforcement may reduce non-compliance (OECD 2000). In the last decade, motivated by improvements in technology that facilitate cross-jurisdiction practice, the

Denise Dickins

dickinsd@ecu.edu

Abdullah Al-Moshaigeh

aalmosh@fau.edu

Julia L. Higgs

jhiggs@fau.edu

1 Florida Atlantic University, Boca Raton, FL, USA

2 East Carolina University, Greenville, NC, USA
AICPA and the National Association of State Boards of Accountancy (NASBA) have promoted legislation through the Uniform Accountancy Act (8th ed.) that allows CPAs licensed in their state of residence to practice in other states. These laws simplify licensing but may complicate enforcement. If not reasonably consistent across BOAs, regulators may be unwilling to delegate responsibility for enforcement to another state's BOA.

There is some evidence of inconsistent enforcement across states. For example, studying state-level sanctions of attorneys, physicians, and CPAs in California, Illinois, New York, and Texas during the period 2008 to 2014, Krom (2019) found that some states were far more likely to bring about a disciplinary action than other states. We investigate a potential explanation of this variation, political influence.

Board members of Federal and state oversight accounting and auditing agencies, including the PCAOB and BOAs, are appointed by politically affiliated, governmental leaders. Since appointees have latitude in matters pursued and penalties assessed, enforcement actions against CPAs may be influenced by politics. We test this hypothesis by comparing the severity of PCAOB sanctions of individual CPAs to the severity of related disciplinary actions of BOAs. 
Extant research on the enforcement activities of the PCAOB, SEC, and BOAs find evidence of meaningful economic penalties. CPA firms sanctioned by the PCAOB lose clients (Beck et al. 2018; Abernathy et al. 2013). CPAs subjected to SEC Accounting and Auditing Enforcement Releases suffer employment restrictions (Juric et al. 2018), and most BOA actions against CPAs include fines (Krom 2016). Interestingly, BOAs are less likely to permanently revoke a CPA's license in cases concerning attestation than for other issues like misdemeanors and felonies (e.g., driving under the influence, Krom 2016).

Investigating the impact of politics on enforcement, Sunstein et al. (2006) find that the political affiliation of judges influences the severity of sentencing, and Cohen and Yang (2019) discover that judges appointed by Republicans impose more severe sentences on black defendants and less severe sentences on women. Our study contributes to this stream of literature about the influence of political affiliation on states' governance of accountants.

We find that when responding to PCAOB sanctions, BOAs under Republican regimes (red states) impose less severe penalties than do BOAs under Democratic regimes (blue states). This finding has public policy implications for, among other things, the monitoring of CPAs taking advantage of mobility laws. Beyond generalized red-state, bluestate differences in enforcement, our results indicate that non-resident CPAs receive less severe sanctions which could threaten the success of mobility laws. Our results also inform the regulatory and enforcement practices of other professions. For example, Gilman (2011) describes how advances in telemedicine complicate enforcement in the practice of medicine.

This paper proceeds as follows. In the next section, we provide background on the responsibilities and enforcement processes of the PCAOB and BOAs, we then develop the study's hypothesis, describe methodology, and present results. Conclusions and suggestions for further research are presented in the paper's final section.

\section{Responsibilities and Enforcement Processes of the PCAOB and BOAs}

Although the PCAOB and BOAs have different responsibilities, both are charged with protecting the public interest. The PCAOB registers CPA firms that perform audits of US publicly traded companies (issuers), conducts inspections of registered CPA firms, sets standards applicable to the audit of issuers, and pursues disciplinary actions when warranted. CPA firms and individuals may be penalized for failing to: (1) adhere to PCAOB auditing standards-which include professional competence, due professional care, and adequately planning and supervising an engagement,
(2) properly evaluate an issuer's application of generally accepted accounting standards, or (3) comply with the CPA firm's own quality control standards. Penalties can include public issuance of findings of non-compliance in an inspection report, private or public release of quality control deficiency notices, and, when considered particularly serious, fines and sanctions temporarily or permanently prohibiting issuer-audits. ${ }^{1}$ The PCAOB has no authority over an individual CPA's license to practice public accounting; licensing is under the purview of state BOAs.

BOAs establish the criteria for when individuals may practice public accounting (i.e., become a CPA), licensing individuals meeting the established criteria, and monitoring licensees for compliance with established rules and regulations. CPAs can be licensed to practice in more than one state. When CPAs violate BOA rules, such as lacking professional competence, failing to exercise due care, or failing to adequately plan and supervise an engagement, they can be subjected to penalties including censure, fines, and/or license revocation.

Rule violations may be brought to a BOAs attention by the PCAOB, SEC, AICPA, or other entities, peer reviews, complaints filed by individuals, self-reports of licensees, or from publicly available information (e.g., legal postings, popular press articles). In some cases, Federal sanctions automatically trigger a BOA disciplinary action (e.g., California, Connecticut, Iowa, New York), but the severity of BOA action can vary. The nature of the matter and available investigatory resources can influence which CPA-related enforcement matters of other agencies a BOA will investigate or defer (Love 2016).

\section{PCAOB Enforcement}

The PCAOB has authority to investigate and discipline registered public accounting firms and persons associated with those firms for non-compliance with its rules, other laws and rules, and professional standards governing the audits of issuers and broker-dealers. ${ }^{2}$ Investigations can be initiated based on the results of its inspections, confidential tips, or its interactions with CPAs of registered firms. The PCAOB's Division of Enforcement and Investigations conducts enforcement activities. When appropriate, its activities are coordinated with other Federal agencies (e.g., SEC, Department of Justice, Financial Industry Regulatory Authority-FINRA). CPAs can settle or litigate the results of an enforcement action.

\footnotetext{
${ }^{1}$ See https://pcaobus.org/Enforcement/Pages/default.aspx.

${ }^{2}$ As prescribed by Sect. 5, Investigations and Adjudications, of Rules of the Board - available at: https://pcaobus.org/Rules/Pages/ Section_5.aspx.
} 
Table 1 PCAOB sanctions by year

\begin{tabular}{rrl}
\hline Year & No. Sanctions & $\begin{array}{l}\text { Political Affili- } \\
\text { ation of US Presi- } \\
\text { dent }\end{array}$ \\
\hline 2005 & 5 & Republican \\
2006 & 3 & Republican \\
2007 & 8 & Republican \\
2008 & 5 & Republican \\
2009 & 8 & Democrat \\
2010 & 7 & Democrat \\
2011 & 7 & Democrat \\
2012 & 12 & Democrat \\
2013 & 10 & Democrat \\
2014 & 6 & Democrat \\
2015 & 27 & Democrat \\
2016 & 25 & Democrat \\
2017 & 37 & Republican \\
2018 (through May & 5 & Republican \\
$23)$ & & \\
Total & 165 & \\
\hline
\end{tabular}

Once the enforcement process is complete, reports of investigations and imposed sanctions are available on the PCAOB's website. As summarized in Table 1, from the date the PCAOB issued its first enforcement report on May 24, 2005, through May 31, 2018 (13 years), 165 US CPAs were sanctioned. The number of CPAs sanctioned in any single year ranged from three to 36 and averaged 12.31. Prior to 2012 , sanctions averaged 6.14 per year, then began to increase dramatically. During the 3 years ended 2017, sanctions averaged 29.67 per year.

This increased enforcement activity is likely associated with two events. First, as required by the Dodd-Frank Act of 2010, inspections of broker-dealers commenced in 2013. Our data include sanctions related to 17 broker-dealer audits during the period 2015 to 2018 , nine of which occurred in 2017, so while this accounts for some increased enforcement activity, it does not explain most of the increase. Second, James Doty was appointed Chairman of the PCAOB in 2011. While not a political appointment (the PCAOB was structured to be shielded from political influence and its members are appointed by the SEC - Coates 2007), at the time, the SEC was comprised of two Republicans, two Democrats, and its Chairman, Independent Mary Shapiro, was appointed by President Obama.

Shortly after his appointment, Doty announced an increased emphasis on enforcement actions (Herron and Gilbertson 2011). Relatedly, findings associated with PCAOB inspections of the Big 4 auditing firms increased from 1.22 per issuer-audit inspected in 2011 and 2012, to 1.63 in 2013 (Boland et al. 2020). As Claudius Modesti served as Director of Enforcement and Investigations from 2004 to 2018, a change in leadership in the PCAOB's enforcement group is not a likely explanation for these changes. Doty was replaced on December 12, 2017 by William D. Duhnke III under President Trump.

While sanctions clearly experienced several distinct periods (pre-Doty, 2005 to 2011; early-Doty, 2012 to 2014; and late-Doty, 2015 to 2018), it is unclear whether there were changes in the severity of the punishment for any given "crime." Sanction reports are structured similarly, but there are likely qualitative factors that go into severity decisions that are not explicitly stated. Without access to the PCAOB's files, it is impossible to know why penalties may differ for a similar infraction. For example, in 2017, a CPA was charged with altering multiple documents and was required to disassociate from his registered firm, a penalty that appears to be the most frequent sanction associated with altering documents. In 2007, a CPA altered the documentation of one audit test and was censured (i.e., told not to repeat the offense), while another CPA also altered documents and was required to disassociate from his registered firm. In 2013, a CPA was found to be a repeat document-altering offender, for which his firm's registration was revoked.

The difference in penalties may be the result of single versus multiple offenses, or lower penalties may be because the CPA cooperated with the investigation, was appropriately humble, did not know the rule, or removed a document believed to be unimportant. More severe penalties are likely reserved for those who did not cooperate with the investigation or intentionally altered the workpapers to hide poor audit work. Presumably, the PCAOB does not impose its most severe penalties on undeserving offenders.

The average time between the date of the financial statements to which sanctions relate, and the date of the sanction report and BOA notification, is less than 3 years. Of the 165 CPAs sanctioned during the 13-year period of our study, 14 chose to adjudicate the PCAOB's assessed penalties. Adjudication increases the time between the date of the financial statements and BOA notification to approximately 5 years.

\section{BOA Enforcement}

States (and US territories) regulate the practice of public accounting. They protect the public interest by licensing individuals qualified to be CPAs and monitoring and enforcing the laws and regulations states enact. In terms of their rules, structure, and activities, BOAs are more similar than different, largely because of the Uniform Accountancy Act. As examples, in addition to a rule requiring licenseecandidates to pass the Uniform CPA Exam, all BOAs require some accounting-related experience to be licensed. Nearly every state requires CPA candidates to have 150 credit hours of higher education; however, only some BOAs require 
licensee-candidates to pass an ethics exam. ${ }^{3}$ Most BOAs have adopted a form of NASBA's Uniform Accountancy Act Model Rule 11.2 that requires CPAs to report within 30 days convictions, judgments, and results of administrative proceedings, including PCAOB sanctions (Love 2016).

In terms of structure, BOA members are directly or indirectly appointed by governors to serve 3- to 5-year terms that allow for reappointment (Dustin 2012). ${ }^{4}$ For example, Florida BOA's website describes that the governor appoints nine board members for up to two consecutive 4-year renewable terms; seven members are certified public accountants licensed in the state who have practiced for at least 5 years (a/k/a members-in-practice) and two are laypersons in unrelated professions. ${ }^{5}$ Five of the six states comprising the most CPAs (New York, Texas, Michigan, Illinois, and Florida) require that a majority of BOA members be members-inpractice. California has a 15-member BOA, of which up to seven may be members-in-practice (California Business and Professions Code $\$ 5000$ a).

BOA members typically volunteer their time and meet monthly to conduct oversight of the BOA's activities, including enforcement. Executive directors are employed to manage day-to-day operations. We discussed the appointment process with three current or past members of two state BOAs who cautioned that, for members-in-practice, recommendations of state CPA societies are equally if not more important than are gubernatorial connections. ${ }^{6}$ To be appointed, members-in-practice must have individual aspiration to serve, availability, and a demonstrated commitment to the profession.

Some BOAs have established Probable Cause (or other disciplinary-focused) committees that may be charged with

\footnotetext{
${ }^{3}$ See ipassthecpaexam.com for a state-by-state comparison of licensee requirements.

${ }^{4}$ Some BOA members are appointed by other state governing bodies, like a board of regents, whose members are appointed by the state's governor (e.g., New York).

${ }^{5}$ See http://www.myfloridalicense.com/DBPR/certified-public-accou nting/board-information/.

${ }^{6}$ The three BOA members are all CPAs, one holds a J.D., and two are academics. It follows that if a state society board is dominated by members of a political party that is different from that of the Governor, that political party could influence BOA actions and our results. There are several reasons why we believe that the results of our analyses are robust for differences in the political party of Governors and state CPA society board members. First, as described, the political party of most states does not change; there are only a handful of "swing states." Since Governors are of the same political party as the majority of state voters, the likelihood is high that the majority of state CPA society boards are of the same political party as the Governor. Second, even if a state society recommends a BOA member, the Governor is not obligated to follow the recommendation. Third, state society board members are volunteers whose appointment is typically voted on or ratified by societies' full memberships which reduces the influence of politics.
}

proactively seeking out rule violations; other BOAs are more reactive in terms of monitoring. As reported by a current BOA member, the number of BOA staff (resources) and number of licensed CPAs (workload) influence how proactive a BOA can be in seeking out rule violations.

The following is a summary description of the Texas BOA's enforcement process: Enforcement staff review a complaint to determine if it involves professional misconduct. If deemed within the BOA's jurisdiction, an investigation file is opened. At the conclusion of the investigation, the BOA's Enforcement Committee reviews findings and offers a consent order containing findings of fact and conclusions of law together with proposed sanctions, administrative penalties, and costs. The CPA has 20 days to accept the consent order or request a hearing. If the CPA does not accept the proposed consent order or fails to request a hearing on a timely basis, the BOA's Executive Director proposes the consent order to the full BOA for approval. ${ }^{7}$ In comparison, although Oregon does not have a separate disciplinary committee, it's process is similar: "[T]he complaints process typically includes four stages: (1) an investigation; (2) a review and recommendation to the board by members of the BOA Complaints Committee; (3) a review and ruling by the board and, with the exception of no violation cases, (4) appeals and settlements with the licensee" (Graham 2014).

While many states have adopted enforcement action guidelines, BOA members have latitude. For example, California's Disciplinary Guidelines and Model Orders (2013, 3) states, "[t]he CBA recognizes that these recommended penalties and conditions of probation are merely guidelines and that mitigating or aggravating circumstances and other factors may necessitate deviations..." Our discussions with BOA members suggest that once a BOA becomes aware of a possible violation of its rules, investigations and related due process are typically completed in less than 1 year, unless adjudicated. Disputed BOA actions can take several years to resolve. California's BOA 2016-2017 Annual Report indicates the time from receipt of a complaint until closure of the investigation averages 154 days, while actions litigated require an average of 969 days. ${ }^{8}$

\section{Hypothesis Development}

Institutional theory helps explain how organizations adapt to their environment. It describes that, "institutions are social structures that have attained a high degree of resilience [and are] composed of cultural-cognitive, normative, and regulative elements that, together with associated activities

\footnotetext{
7 See http://www.tsbpa.texas.gov/enforcement/filing-complaint.html.

${ }^{8}$ See https://www.dca.ca.gov/cba/communications-and-outreach/ annual_rpt_2017.pdf.
} 
and resources, provide stability and meaning to social life" (Scott 2008, p. 48). A key insight of institutional theory is that norms and routines, including enforcement, that become established as authoritative guidelines do not necessarily optimize decision-making (Marquis and Tilcsik 2016). Organizations compete for political power and legitimacy to attain and retain social and economic fitness (DiMaggio and Powell 1983).

BOAs are organizations comprised of individuals appointed by political actors. BOA members' worldviews, allegiances, and resource availability (e.g., information, time, funding) likely impact their decisions. An individual's worldview is the product of native customs, religion, parental guidance, and socio-economic status, all of which likely influence political party affiliation. ${ }^{9}$ Responding to the question, "What is closer to your point of view: Government should do more to solve problems and help meet the needs of people, or government is doing too many things better left to businesses and individuals," 76 percent of individuals identifying as Republican said the government should do less, and 75 percent of Democrats said the government should do more (Seib 2012); and over the last decade these differences have hardened (Seib 2019). Political views and politics have been found to impact social, economic, and judicial decisions. As examples, during the 2020 Covid-19 crisis, the states less likely to adopt stay-at-home orders were headed by Republican governors (Klebnikov 2020), and comparing similar crimes, judges appointed by Republicans impose more severe sentences on black defendants and less severe sentences on women (Cohen and Yang 2019).

From a business perspective, the worldview of Republicans tends to be more "business friendly," favoring a purer form of capitalism over governmental control and regulation; while the worldview of Democrats tends to favor some level of governmental regulation to protect the public against the negative impacts of unbridled capitalism. Although Republicans have been labeled "tough on crime," crimes punished are less likely to be "white-collar" (Rampell 2018). The SEC's Final Rule: Retention Audit and Review Records (17 CFR Part 210) requires auditors to retain for 7 years certain records relevant to their audits and reviews of issuers' financial statements, making altering documents during or in anticipation of a review by the PCAOB a white-collar, civil

\footnotetext{
9 An individual's worldview also impacts career choice. Studies have shown that accountants tend to fall into categories on various Jungian-based personality tests that describe their personality traits as cautious, deliberate, analytical, and questioning (among others, Shackleton 1980; Schloemer and Schloemer 1997; Burton et al. 2016). Perhaps not surprising, data of the Federal Election Commission reported by Verdant Labs reports approximately 60 percent of CPAs are registered Republicans (See http://verdantlabs.com/polit ics_of_professions/).
}

crime. In a case where this law is violated, the findings of Rampell (2018) suggest that Republican regimes may favor a less severe reaction to a sanction from a Federal-level regulator like the PCAOB.

BOA members gain their political power from the governor that appoints them. If a state CPA society board recommends a member-in-practice for appointment, the governor and candidate may not have had any previous interaction. If they share a political party, this is likely to generate some commonality, but it is appointment to the BOA and the granting of political power that generates or strengthens allegiance to both the governor and other BOA members. Membership in the same political party strengthens, but is not a necessary condition for allegiance, social identity, and groupthink to influence thinking. Allegiances and group affiliations impact attitudes and behaviors (Cialdini and Goldstein 2004; Gerber et al. 2008). Social identity theory (Tajfel and Turner 1979, 1986) posits that an individual's self-concept is, in part, described by membership in a relevant social group; it helps explains intergroup behavior like in-group bias and has been found to be a significant predictor of political party ideology and activities (Greene 2004). Janis (1982) was the first to describe the sociological theory, groupthink, which occurs when group members seek consensus by suppressing dissenting viewpoints. It promotes in-group bias and underrates the views of out-groups. Group member cohesiveness, situational context, and resource availability influence whether it is likely to occur. Recall that most BOA members are volunteers with full-time jobs. Importantly, allegiance to one group does not prohibit allegiance to another. Member-in-practice BOA members can adhere to the AICPA's Code of Professional Conduct, have allegiance to other BOA members, and have either conservative or liberal tendencies. They can also fall victim to sub-optimal decision-making strategies.

Wittman (1983) asserts that politicians are motivated by policy preferences. Republican leaders tend to enact fiscal retrenchment (Gelman 2009), and public sector spending is higher in states with more liberal political elites (Lowry 2013). Ergo, less of a state's budget may be allocated to monitoring activities under more business-friendly Republican regimes. Although many BOAs are self-funded by the fees charged CPAs, they are state agencies and are therefore likely to be at least influenced by state budgetary expectations. As an example, in 2010 California's BOA (CBA) reduced its initial licensing and renewal fees to help offset the negative impacts of the then-current economic climate and offset expenses associated with a new peer review requirement (CBA 2010). At the time, Schwarzenegger, a Republican, was governor. When fewer regulatory resources are available, efficient allocation strategies (i.e., heuristics) are more highly relied upon, decreasing the likelihood of unbiased decisions (Kahneman and Klein 2009; Bazerman 2017). 
Meier (1991) asserts regulation is inherently a political process where the actors (in our case, BOAs, CPAs, consumers of accounting services, and politicians) seek to allocate power of the state for their own benefit; the regulatory objective of protecting consumers may conflict with the goals of the actors. One goal of politicians is reelection. Black's (1948) median voter theorem posits that because politicians are primarily motivated to hold office, we should expect no differences based on political affiliation. Leigh's (2008) findings support this premise; he finds no relationship between a state governor's political party and 26 of 32 outcomes ranging from corporate tax rates to welfare caseloads. Similarly, Helland (1998) found that having a Democrat governor had no effect on the probability that a plant received a clean water inspection by the state; and Elrod et al. (2018) found that although states with Democrat governors inspect a smaller percentage of their major water polluters, enforcement actions did not vary based on political affiliation. On the other hand, Devlin (2002) found no-fault auto insurance provisions, which are viewed as a type of government intervention, were more likely than strict-liability provisions in states led by Democrat governors.

Collectively, the influence of board members' worldviews, allegiances, and resource availability lead us to hypothesize,

$\mathrm{H}$ : When responding to $\mathrm{PCAOB}$ sanctions, BOAs serving under Republican regimes will impose less severe penalties than BOAs under Democratic regimes.

\section{Methodology}

Our hypothesis is addressed by comparing publicly available data about US CPAs sanctioned by the PCAOB during the period May 24, 2005, to May 23, 2018 (13 years) to the subsequent actions of the CPAs BOA(s). Using May 2018 as the endpoint of our analyses allows for the expected time lag between PCAOB sanctions and BOA actions. Of the 165 individual CPAs sanctioned during the period of our analyses, 44 were licensed in more than one state, resulting in a total of $234 \mathrm{BOA}$ actions. ${ }^{10}$

\footnotetext{
$\overline{10}$ Registered firms are also sanctioned by the PCAOB, as when violations are attributed to failures in firms' quality control processes. In many of the 165 sanctions examined here, both the CPA and their registered firm are sanctioned. Our analyses are restricted to comparing the relationship between PCAOB sanctions and BOA actions for CPAs because, as confirmed by discussions with three current and former BOA members, state-level enforcement actions against CPAs carryover to their firms in part due to states' "holding out" regulations. For example, if John Doe's CPA license is revoked, so is that of his sole-practitioner firm, John Doe CPA. If his firm is a partnership, Doe and Smith CPAs, his firm must change its name or become a different firm. BOAs rarely impose actions against firms separate from their firm-member CPAs. At the state level, firm licensing/registra-
}

Table 2 reports BOA actions by the CPA's licensing state(s). For each state, it also provides data about governors' political affiliations, CPA licensees, and issuers. BOA actions cover 35 states with CPA licensee populations that range in size from 1190 (Wyoming) to 101,709 (New York $)($ mean $=21,186$, median $=9785)$. Six states comprise approximately one-half of CPAs: New York, California, Texas, Michigan, Illinois, and Florida. The number of issuers ranges from two (Wyoming) to 1203 (New York) (mean $=253$, median $=76$ ). Four states represent approximately 50 percent of issuers: New York, California, Texas, and Massachusetts.

In general, we expect to find that states with the greatest number of CPAs and issuers are associated with a larger number of BOA actions related to PCAOB sanctions, but this may not always be the case. For example, licensee data include both active and inactive CPAs. Active status requires the completion of continuing professional education and paying annual fees but does not require that a CPA either perform an audit or prepare a tax return. States with larger populations of retirees may have a greater number of inactive CPAs or active CPAs who no longer practice public accounting. Also, active CPAs do not necessarily perform issuer-audits; many only prepare tax returns, perform accounting services, or perform audits of privately held entities. All that said, our data suggest BOA actions are highly correlated with the number of CPAs in each state $(r=0.77$, $p<0.001)$ and the number of issuers in each state $(r=0.81$, $p<0.001)$. Considering its population of CPAs, many of whom are presumably inactive retirees, and its number of issuers, Florida appears to have a disproportionate number of PCAOB-sanctioned CPAs $(n=23)$. Given its CPA and issuer populations, Utah also appears to have more than its fair share of sanctioned CPAs $(n=14)$.

During the period of our analyses, 16 states (46 percent) were led by Republican governors, 12 (34 percent) were led by both Republican and Democrat governors, and seven ( 20 percent) were led by Democrat governors. Of the 234 BOA actions, 128 (55 percent) were issued under Republican governors, and 106 (45 percent) were issued under Democrat governors (not tabulated). ${ }^{11}$

\section{Footnote 10 (continued)}

tion is primarily for monitoring unlicensed activity by non-CPAs and "holding out" rules.

11 The 234 BOA Actions are classified as Red (or not) based on the date of the action. During the period of our analyses, only three states were affiliated with Independent Party governors. Two had no PCAOB sanctions (Alaska and Rhode Island), and one (Florida) elected a Republican governor in 2007 who changed his political affiliation to Independent in May 2010 (Charlie Christ) — the last of his 4-year term. Our dataset includes two Florida BOA actions in 2010, one of which is dated March 19. The other is of a non-resident, for which no action was taken. These BOA actions have been classified as Red. 
Table 2 BOA Actions by CPA License State

\begin{tabular}{|c|c|c|c|c|}
\hline State & Political Affiliation ${ }^{a}$ & BOA Actions ${ }^{\mathrm{b}}$ & $\begin{array}{l}\text { CPAs licensed in } \\
\text { State }^{c}\end{array}$ & Issuers in State ${ }^{\mathrm{d}}$ \\
\hline Arkansas & Red & 1 & 5847 & 19 \\
\hline Arizona & Red/Blue & 8 & 11,221 & 132 \\
\hline California & Red/Blue & 27 & 94,727 & 1182 \\
\hline Colorado & Blue & 12 & 18,960 & 310 \\
\hline Connecticut & Blue & 1 & 10,536 & 146 \\
\hline Delaware & Blue & 1 & 2267 & 155 \\
\hline Florida & Red & 23 & 36,523 & 373 \\
\hline Georgia & Red & 3 & 20,766 & 156 \\
\hline Illinois & Red/Blue & 8 & 36,911 & 416 \\
\hline Indiana & Red & 3 & 12,166 & 81 \\
\hline Iowa & Red/Blue & 3 & 6553 & 45 \\
\hline Kansas & Red/Blue & 2 & 7958 & 50 \\
\hline Kentucky & Blue & 3 & 8247 & 40 \\
\hline Louisiana & Red & 1 & 10,385 & 32 \\
\hline Maryland & Red/Blue & 3 & 20,114 & 194 \\
\hline Massachusetts & Red/Blue & 6 & 18,203 & 680 \\
\hline Michigan & Red/Blue & 4 & 42,868 & 92 \\
\hline Missouri & Blue & 5 & 3859 & 77 \\
\hline Nebraska & Red & 3 & 4363 & 52 \\
\hline Nevada & Red & 12 & 3264 & 175 \\
\hline New Hampshire & Red & 1 & 5052 & 12 \\
\hline New Jersey & Red & 13 & 27,596 & 303 \\
\hline New York & Red/Blue & 30 & 101,709 & 1203 \\
\hline North Carolina & Red/Blue & 5 & 21,163 & 124 \\
\hline Ohio & Red & 2 & 32,964 & 210 \\
\hline Oklahoma & Red & 2 & 10,952 & 49 \\
\hline Oregon & Blue & 1 & 7802 & 35 \\
\hline Pennsylvania & Red/Blue & 8 & 26,328 & 414 \\
\hline South Carolina & Red & 1 & 6211 & 27 \\
\hline Texas & Red & 11 & 68,425 & 691 \\
\hline Utah & Red & 14 & 5664 & 76 \\
\hline Virginia & Red/Blue & 3 & 27,628 & 152 \\
\hline Washington & Blue & 10 & 18,771 & 112 \\
\hline Wisconsin & Red & 3 & 12,279 & 118 \\
\hline Wyoming & Red & 1 & 1190 & 2 \\
\hline Sub-total & & 234 & 741,522 & 7935 \\
\hline Other 20 states $^{\mathrm{e}}$ & & 0 & 91,603 & 360 \\
\hline Total & & 234 & 833,152 & 8295 \\
\hline
\end{tabular}

${ }^{\text {a }}$ Political party(ies) of the governors during the period of our analyses

${ }^{b}$ Related to CPAs sanctioned by the PCAOB from May 2005 to May 2018. Available at: PCAOB.org

${ }^{\mathrm{c}}$ Data provided by NASBA for 2017 (except Delaware and Utah which are for 2016). Includes active and inactive CPAs. As of April 22, 2016, there were 664,532 US active CPAs (see: https://nasba.org/app/uploa ds/2016/05/PR_Official-Active-CPA-Statistic-Press-Release_Final-052416.pdf), suggesting that approximately $80 \%$ of these CPA data are active CPAs

'Data from Audit Analytics based on US issuers' 2017 annual reports

${ }^{\mathrm{e}}$ Excludes US territories

\section{Data}

To test the study's hypothesis, we first gather data about the nature and severity of each PCAOB sanction and each BOA action. Examples of the activities that may result in PCAOB sanctions and a summary of the 165 sanctions issued during the period of our analyses are provided in Table 3. PCAOB sanctions are categorized in order of severity as: censure $=1$, 
continuing professional education $=2$, fine $=3$, temporary suspension of activities $=4$, and bar from association with the CPA's registered firm or revocation of the registration of the CPA's firm $=5 .{ }^{12}$ This severity ordering is consistent with descriptions provided by the PCAOB. For example, the PCAOB's website explains it, "may impose a range of sanctions on an auditor, including a censure, monetary penalties, revocation of a firm's registration, and a bar on an individual's association with registered accounting firms." 13

When a CPA receives multiple sanctions, the most severe is used in our analyses. For example, a CPA both fined and barred is categorized as " 5 " in Table 3 . As depicted, during the period of our analyses sanctions of CPAs were most frequently categorized as " 5 " ( $n=123,74$ percent). Fines ranged from zero to $\$ 100,000$ (not tabulated, mean $=\$ 6,485$, median $=\$ 0$ ).

The PCAOB can charge CPAs with a variety of infractions including lack of independence, inadequate documentation, failing to adhere to auditing standards, lack of skepticism or due care, altering documentation, or failing to cooperate with inspectors, among others. Our coding system finds the 165 CPAs included in our study were charged with a total of 379 violations (range of 1 to 8 , mean $=2.41$ ). Of these violations, the most frequently cited was lack of skepticism or due care $(n=87)$. The number of violations cited is correlated with the most severe sanctions (Category 5 in Table 3, $r=0.259, p<0.001$ ), and the violation associated with the most severe sanctions is altering documents $(r=0.143, p<0.05)$. This finding is consistent with the heightened emphasis the PCAOB has placed on the importance of not altering documentation as summarized in its Staff Audit Practice Alert No. 14, Improper Alteration of Audit Documentation, issued on April 21, 2016.

For each PCAOB sanction, we next collected data on related actions of the CPAs' respective BOA(s) $(n=234)$. These data are from several sources including the website CPAVerify, NASBA (nasba.org), individual BOA websites, and when necessary, Freedom of Information Requests of

\footnotetext{
12 "Bar" is most commonly associated with CPA-employees or partners of larger firms, and "revocation" is most commonly associated with CPA-partners of smaller firms. In some cases, the PCAOB sanctions both the CPA and the CPA's firm; for example, when poor quality controls over the firm's processes contributed to the matter. When firms are small, disentangling fines between the CPA and his or her firm is difficult. Also, perhaps as a way of penalizing all partners, the fines assessed annually inspected firms can be very large. Related to our dataset of PCAOB sanctions against individual CPAs, four annually inspected firms were assessed fines that ranged from $\$ 1,000,000$ to $\$ 2,000,000$. Excluding these large firm fines, related firm fines ranged from zero to $\$ 20,000$ (mean $=\$ 3515$, median $=\$ 0)$.

13 See https://pcaobus.org/enforcement/Pages/default.aspx.
}

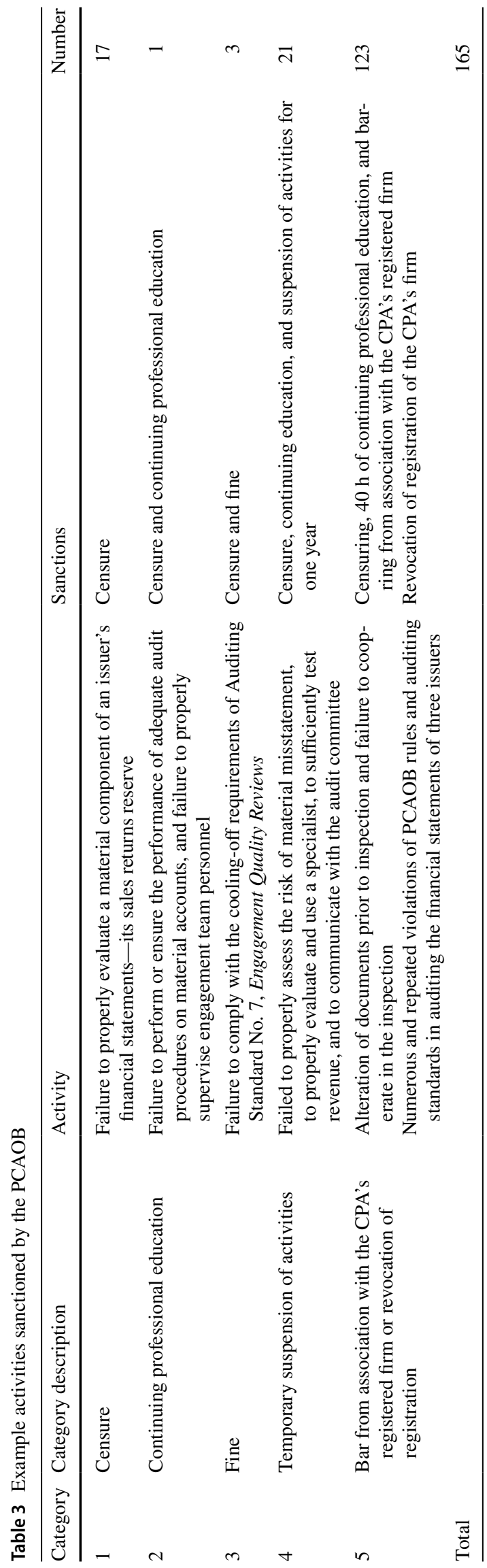


Table 4 BOA actions by type

\begin{tabular}{|c|c|c|c|}
\hline Category & Sanction & Description & Number \\
\hline 0 & No action & $\begin{array}{l}\text { No action was taken and the CPA's license is still active in } 2019 \text {, or the CPA's license } \\
\text { lapsed or otherwise deactivated without a fine or other penalty }\end{array}$ & 78 \\
\hline 1 & Reprimand & The CPA was told not to commit the act again & 8 \\
\hline 2 & Continuing professional education & $\begin{array}{l}\text { The CPA was required to take course work in excess of the regular annual or bi-annual } \\
\text { state requirements }\end{array}$ & 1 \\
\hline 3 & Fine or probation & $\begin{array}{l}\text { The CPA was assessed a monetary fee of at least } \$ 1,000 \text { or was assigned to a watchlist } \\
\text { for a period and may have been subjected to a peer review of other engagements dur- } \\
\text { ing which time the CPA may have been unable to perform certain services }\end{array}$ & 73 \\
\hline 4 & Temporary suspension of license & $\begin{array}{l}\text { The CPA was prohibited from performing any services for a period (typically, } 2 \text { to } \\
5 \text { years) }\end{array}$ & 42 \\
\hline 5 & Revocation of license & The CPA is permanently prohibited from performing accounting services in the state & 32 \\
\hline Total & & & $234 *$ \\
\hline
\end{tabular}

*The total number of observations used in the study's analyses $(n=234)$ is greater than the number of PCAOB sanctions summarized and classified in Table $3(n=165)$ due to some CPAs being registered to practice in more than one state

BOAs. ${ }^{14}$ BOA actions most frequently occur within 1 year of notification by the PCAOB (79 percent), but can take up to 5 years when adjudicated. One BOA member described that the most severe matters typically take the longest to resolve.

As summarized in Table 4, BOA actions are categorized in order of severity as: no action $=0$, meaning the BOA took no action and the CPA's license is still active in 2020 or the CPA's license lapsed or otherwise deactivated without a fine or other penalty; reprimand $=1$, meaning the CPA was told not to commit the act again; continuing professional education, meaning the CPA was required to take course work in excess of the regular annual or bi-annual state requirements $=2$; fine of at least $\$ 1,000,{ }^{15}$ or probation, typically meaning the CPA was assigned to a watchlist for a period and may have been subjected to a peer review of other engagements during which time the CPA may have been unable to perform certain services $=3$; temporary suspension of license $=4$, meaning the CPA is prohibited from performing any services for a period (typically 2 to 5 years); and revocation of license $=5$; meaning the $\mathrm{CPA}$ is permanently prohibited from performing accounting services in the state.

As far as we can tell, our severity ordering is consistent with reports of the BOAs of the six states comprising the most CPAs (New York, California, Texas, Michigan, Illinois, Florida). For example, Florida's Administrative

\footnotetext{
${ }^{14}$ Spencer et al. (2015) provide information on data available about disciplinary actions at BOA websites. For future researchers, we found that their data continue to be reliable for the 30 states represented in our analyses except for Colorado, Florida, North Carolina, and Texas. These states now include finalized disciplinary actions on their website.

15 Utah's standard agreement requires that disciplined CPAs reimburse costs but does not specify the amount of such costs. We assume these costs are less than $\$ 1,000$.
}

Chapter 61H1-36.004 describes, "All penalties at the upper range of the sanctions set forth in the guidelines, i.e., suspension, revocation, etc., include lesser penalties, i.e., fine, probation or reprimand which may be included in the final penalty at the board's discretion." Our coding is also intended to align with the severity ordering of PCAOB sanctions.

As summarized in Table 4, BOAs most frequently respond to PCAOB sanctions by taking no action $(n=78$, 33 percent), closely followed by assessing a fine or imposing probation $(n=73,31$ percent $)$.

\section{Model}

The model for testing our hypothesis presumes the severity of BOA actions is a function of the severity of the PCAOB sanction, BOA characteristics, PCAOB sanction characteristics, and CPA characteristics (individual variables used in the equation are italicized):

$$
\begin{aligned}
\text { BOA Action }= & B_{0}+\alpha_{1} \text { PCAOB Sanction }+\alpha_{2} \text { Red BOA } \\
& + \text { BOA Characteristics } \\
& + \text { PCAOB Sanction Characteristics } \\
& + \text { CPA Characteristics }+\varepsilon,
\end{aligned}
$$

where $B O A$ Action and $P C A O B$ Sanction are continuous variables of severity of the ordered categorization of BOA actions (Table 4, range 0-5) and PCAOB sanctions (Table 3, range $1-5) .{ }^{16}$ We expect the coefficient on $P C A O B$ Sanction will be positive.

\footnotetext{
${ }^{16}$ For 11 observations, BOA action is more severe than PCAOB sanction. Since in each of these matters the CPA had prior BOA violations and the action was for multiple infractions, we code these observations as equal in severity.
} 
Red BOA is the variable of interest. It is an indicator equal to one if the governor of the state where the CPA is licensed was a Republican at the date of BOA action; otherwise, it is equal to zero. We use the political party of the governor as he or she directly or indirectly appoints BOA members, typically appoints the executive director, and directs the budget which influences the amount of resources spent on investigating complaints. Importantly, although governors are elected every 4 years, as depicted in Table 2, over the last two decades, most states' political party affiliations have been consistent. Even when the governor changes, the political party has nearly always stayed the same-perhaps due to increased gerrymandering (Graham and Svolik 2020; Short 2018; Newkirk 2017). In the event of a change in the political party, since groupthink and budgetary resources are largely related to the current governor, even a holdover board member appointed by a governor of a different party will likely be influenced by the current political climate. If, as hypothesized, Red BOA reduces the severity of $\mathrm{BOA}$ actions made in response to PCAOB sanctions, its coefficient will be negative.

Several other influential BOA characteristics are included in the regression equation. First, two variables are included to control for a BOA's workload and experience with PCAOB sanctions: \#CPAs and \#Issuers. \#CPAs is an indicator variable equal to one if the number of CPAs in the state is greater than 10,000 (based on the median of 9785); otherwise, it is equal to zero. \#Issuers is an indicator variable equal to one if the number of issuers in the state is greater than 100 (based on the median of 76); otherwise, it is equal to zero. We predict that increased workloads will decrease the severity of $B O A$ Action, and more experience with PCAOB sanctions will increase the severity of $B O A$ Action. Second, a state's budget likely impacts the resources available for enforcement. We include State GDP in the regression equation which is a state's gross domestic product in the year of action, divided by the state's population, but make no prediction about the direction of its coefficient. ${ }^{17}$

Other than severity, PCAOB sanction characteristics considered in the equation are the length of the enforcement process and regime. As described by a BOA member, more serious matters typically take longer to resolve. It is possible that BOAs may be less likely to forgive more serious infractions. Alternatively, it is possible that the passage of time makes BOAs more forgiving. A BOA member offered that by the time some PCAOB sanctions are reviewed, Federal-level penalties have already been served (presumably, Table 3,

\footnotetext{
17 An alternative to including these proxies for differences in BOA characteristics is to include fixed effects indicator variables for each of the 30 states represented by the BOA actions included in our dataset. Because our dataset includes only 234 observations, doing so would greatly reduce the power of the study's analyses.
}

Category 4-temporary suspension of activities, $n=21$ ). Imposing a BOA action extends the penalty already served, which BOAs "are loathe to do." To capture the impact of the length of the enforcement process, we include Lag in the equation which is equal to the time between the year of the PCAOB sanction and the year of the BOA action but make no prediction about the direction of its coefficient.

As discussed above, there are three distinct periods of PCAOB enforcement activities: pre-Doty (2005 to 2011, $n=65$ ), early-Doty (2012 to $2014, n=44)$, and late-Doty (2015 to $2018, n=125$ ). It is possible that in addition to changes in the frequency of enforcement actions during these time periods, there were also changes in the severity of PCAOB sanctions. If true, this could impact the relationship between the severity of PCAOB sanctions and the severity of BOA actions. Two indicator variables are included in the equation to control for these fixed effects, if any (Pre-Doty, Late-Doty). ${ }^{18}$ We make no prediction about the direction of the coefficients on these indicator variables.

Lastly, individual CPA characteristics are included in the regression equation. These are: residency status of the CPA, gender, age, and size of firm. It may be that BOA resources are allocated differently between resident and non-resident CPAs. To account for this possibility, we include an indicator variable, Non-resident $C P A$, in the regression equation if the BOA is not located in the CPAs state of residence. Gender is an indicator variable equal to one if the CPA is a woman, otherwise is equal to zero. Age at the date of the PCAOB sanction is a continuous variable, and size of firm is an indicator variable equal to one if the CPA's firm is annually inspected, otherwise it is equal to zero (Firm Size). We make no prediction about the direction of the coefficients on these variables.

\section{Results}

Descriptive statistics of the variables used to estimate the study's equation are presented in Table $5(n=234)$. Red states have slightly more BOA actions (55 percent). Providing initial evidence in support of our hypothesis, although the average severity of PCAOB sanctions is not statistically different comparing red and blue states (difference of 0.03), BOA actions are significantly less severe comparing red and blue states (difference of $-0.98, p<0.001){ }^{19}$

\footnotetext{
18 An alternative to using indicator variables to control for the three periods would be to include fixed effects indicator variables for each of the 13 years considered in the study. Because our dataset includes only 234 observations, doing so would greatly reduce the power of our analyses.

19 Consistent with this finding, a transcript of the continuing professional education course, Ethics: Protecting the Integrity of Florida CPAs (2018-19) (available at: https://ficpa.org/Public/Products/Produ
} 
Table 5 Descriptive statistics

\begin{tabular}{llcccc}
\hline Variable & Range & \multicolumn{2}{l}{ Mean } & Difference \\
\cline { 3 - 5 } & & $\begin{array}{l}\text { All } \\
(n=234)\end{array}$ & $\begin{array}{l}\text { Red } \\
(n=128)\end{array}$ & $\begin{array}{l}\text { Blue } \\
(n=106)\end{array}$ & \\
\hline BOA Action & 0 to 5 & 2.38 & 1.94 & 2.92 & $-0.98^{* * *}$ \\
PCAOB Sanction & 1 to 5 & 4.44 & 4.45 & 4.42 & 0.03 \\
\#CPAs & 0 or 1 & 0.79 & 0.72 & 0.89 & $-0.17^{* * *}$ \\
\#Issuers & 0 or 1 & 0.81 & 0.74 & 0.89 & $-0.15^{* *}$ \\
State GDP & $36(\mathrm{KY})$ to $86(\mathrm{NY})$ & 57.47 & 51.80 & 64.31 & $-12.51^{* * *}$ \\
Lag & 0 to 6 & 0.90 & 0.73 & 1.10 & $-0.37^{*}$ \\
Pre-Doty & 0 or 1 & 0.28 & 0.23 & 0.33 & -0.10 \\
Late-Doty & 0 or 1 & 0.53 & 0.54 & 0.52 & 0.02 \\
Non-resident CPA & 0 to 1 & 0.29 & 0.27 & 0.33 & -0.06 \\
Gender & 0 to 1 & 0.09 & 0.06 & 0.13 & -0.07 \\
Age & 27 to 80 & 54.32 & 54.16 & 54.52 & -0.36 \\
Firm size & 0 to 1 & 0.16 & 0.13 & 0.19 & -0.06 \\
\hline
\end{tabular}

$B O A$ Action is a continuous variable of the ordered categorization of BOA actions (Table 5, range 0 to 5)

$P C A O B$ Sanction is a continuous variable of the ordered categorization of PCAOB sanctions (Table 4, range 1 to 5)

${ }^{\#} C P A s$ is an indicator variable equal to one if the number of CPAs in the state is greater than 10,000 , otherwise it is equal to zero

${ }^{\#}$ Issuers is an indicator variable equal to one if the number of issuers in the state is greater than 100, otherwise it is equal to zero

Lag is the number of years between the PCAOB sanction and the BOA action

Pre-Doty and Late-Doty are fixed effect indicator variables representing the three (minus one) time periods included in the study's analyses

Non-resident CPA is an indicator variable equal to one if the BOA is not located in the CPAs state of residence, otherwise it is equal to zero

Gender is an indicator variable equal to one if the CPA is a woman, otherwise is equal to zero

Age at the date of the PCAOB sanction is a continuous variable

Firm Size is an indicator variable equal to one if the CPA's firm is annually inspected, otherwise it is equal to zero

$*, * *, * *$ Significant at $p<0.05, p<0.01, p<0.001$, respectively (two-tailed)

Blue states are larger than red states in terms of the number of CPAs, number of issuers, and GDP (differences range from $p<0.01$ to $p<0.001)$, and these BOA characteristics are highly correlated ( $r=0.36$ to 0.69 , all $p<0.001$, not tabulated). The average time between PCAOB sanctions and BOA actions is less than 1 year $(\operatorname{Lag}$ mean $=0.90)$, which is longer in blue states than in red states $(p<0.05)$. Of the BOA actions, 29 percent were in the Pre-Doty period, and 53 percent were in the Late-Doty period, leaving 18 percent in the Early-Doty period. There are no differences in these PCAOB sanction characteristics comparing red and blue states.

\section{Footnote 19 (continued)}

ctDetailsv3.aspx?ProductID=ETHOL18) reports that revocations (Category 5, Table 4) are rare, and long suspensions (Category 4, Table 4) may be used to prevent CPAs from practicing while enabling the BOA to maintain jurisdiction over the CPA
There is also no difference between red and blue states comparing CPA characteristics. Approximately 29 percent of BOA actions are related to non-resident CPAs. Of these, 48 percent are BOA "no actions" (not tabulated). In comparison, 27 percent of home-state BOA actions are "no actions," a significant difference $(p<0.01)$. Nine percent of all BOA actions are imposed on women, the average age of impacted CPAs is 54 , and 16 percent are imposed on firms annually inspected by the PCAOB.

Results of the estimation of the study's equation are reported in Table 6. The equation explains a significant amount of the variation in BOA Action $\left(\operatorname{adj}-\mathrm{R}^{2}=0.411\right.$, $p<0.001$ ) and variance inflation factors are all under three, suggesting multicollinearity between the independent variables is not unduly impacting the results. As presented in Column A, the coefficient on Red BOA is significantly negative controlling for the severity of the PCAOB Sanction, BOA characteristics, PCAOB sanction characteristics, and CPA characteristics $(p<0.001)$. Consistent with our 
Table 6 Results of Estimation of the Study's Equation $(n=234)$

\begin{tabular}{llccc}
\hline Variable & Predicted sign & $\mathrm{A}$ & $\mathrm{B}$ & $\mathrm{C}$ \\
\hline Intercept & & 1.791 & 1.861 & 1.788 \\
PCAOB Sanction & + & $0.483^{* * *}$ & $0.483^{* * * *}$ & $0.479^{* * *}$ \\
Red BOA & - & $-0.861^{* * *}$ & $-0.873^{* * *}$ & $-0.858^{* * *}$ \\
\#CPAs & - & $-1.593^{* * *}$ & $-1.598^{* * *}$ & $-1.601^{* * *}$ \\
\#Issuers & + & $1.017^{* *}$ & $1.029^{* *}$ & $1.029^{* *}$ \\
State GDP & \pm & -0.010 & -0.011 & -0.010 \\
Lag & \pm & $0.717^{* * *}$ & $0.717^{* * *}$ & $0.718^{* * *}$ \\
Pre-Doty & \pm & 0.179 & 0.170 & 0.163 \\
Late-Doty & \pm & -0.136 & -0.151 & -0.151 \\
Non-resident CPA & \pm & $-0.577^{* *}$ & $-0.585^{* *}$ & $-0.574^{* *}$ \\
Gender & \pm & 0.078 & 0.079 & 0.063 \\
Age & \pm & -0.010 & -0.011 & -0.010 \\
Firm size & \pm & -0.315 & -0.314 & -0.297 \\
BD & \pm & & 0.083 & \\
2CPAs & \pm & & 0.090 \\
Adj-R & & & 0.408 & 0.408 \\
\hline
\end{tabular}

Dependent Variable $=$ BOA Action

$B O A$ Action is a continuous variable of the ordered categorization of BOA actions (Table 5, range 0 to 5 )

$P C A O B$ Sanction is a continuous variable of the ordered categorization of PCAOB sanctions (Table 4, range 1 to 5$)$

Red BOA is an indicator variable equal to one if the governor of the state where the CPA is licensed was a Republican at the date of BOA action, otherwise it is equal to zero

${ }^{\#} C P A s$ is an indicator variable equal to one if the number of CPAs in the state is greater than 10,000 , otherwise it is equal to zero

${ }^{\#}$ Issuers is an indicator variable equal to one if the number of issuers in the state is greater than 100 , otherwise it is equal to zero

Lag is the number of years between the PCAOB sanction and the BOA action

Pre-Doty and Late-Doty are fixed effect indicator variables representing the three (minus one) time periods included in the study's analyses

Non-resident CPA is an indicator variable equal to one if the BOA is not located in the CPAs state of residence, otherwise it is equal to zero

Gender is an indicator variable equal to one if the CPA is a woman, otherwise is equal to zero

Age at the date of the PCAOB sanction is a continuous variable

Firm Size is an indicator variable equal to one if the CPA's firm is annually inspected, otherwise it is equal to zero

$B D$ is an indicator variable equal to one if the PCAOB sanction relates to the audit of a broker-dealer, otherwise it is equal to zero

$2 C P A s$ is an indicator variable equal to one if two or more CPAs in a state are associated with the same PCAOB sanction; otherwise, it is equal to zero

*, **, ***Significant at $p<0.05, p<0.01, p<0.001$, respectively (two-tailed) hypothesis, BOA actions made in response to PCAOB sanctions are less severe in red states.

Individual state-level observations included in our dataset are representative of this result. For example, from 2008 to 2010, California had a Republican governor and its BOA responded less severely to the three PCAOB sanctions addressed during these years. In contrast, from 2011 to 2013, California had a Democrat governor and responded to three PCAOB sanctions, but each BOA action was as severe as its related PCAOB sanction. Pennsylvania is another state that had both red and blue governors during the period of our analysis. From 2003 to 2010, Pennsylvania had a Democrat governor and its BOA responded more severely to the sanctioning of two CPAs by the PCAOB. In comparison, when its governor was Republican from 2011 to 2014, its BOA responded to four PCAOB sanctions with "no action."

As predicted, results suggest BOA workloads (\#CPAs) decrease the severity of BOA actions $(p<0.001)$, and BOA experience (\#Issuers) increases severity $(p<0.01)$. Two 
other control variables significantly influence $B O A$ Action: Lag and Non-resident CPA. The coefficient on Lag is significantly positive, suggesting longer BOA investigations increase severity $(p<0.001)$, and the coefficient on Non-resident $C P A$ is significantly negative suggesting non-resident CPAs are penalized less severely $(p<0.01)$.

An example from our dataset demonstrates the impact of non-resident status and a state's political affiliation. In 2017, a CPA was sanctioned by the PCAOB for repeatedly violating $\mathrm{PCAOB}$ rules and standards. For this infraction, he was barred from association with his firm (Category 5 , Table 3). At the time, the CPA was licensed in his home state of New Jersey (red) and in New York (blue). The New Jersey took no action (Category 0, Table 4), while the New York BOA revoked his license (Category 5, Table 4). As another example, in 2009 while licensed in her home state of Arizona (red) and in California (blue), a CPA was sanctioned by the PCAOB for failing to "perform sufficient auditing procedures" and "appropriately address departures from GAAP," for which she was barred from association with her firm (Category 5, Table 3). In Arizona, the CPA was suspended from performing services (Category 4, Table 4) and in California, she was required to surrender her license (Category 5, Table 4).

Ad hoc analyses correlating CPA characteristics variables with PCAOB sanctions and BOA actions separately, we find women and CPAs under age 40 are less severely sanctioned by the PCAOB $(r=-0.143, p<0.05$, and $r=-0.361$, $p<0.001)$. It may be that they commit less egregious errors, or it may be that younger CPAs hold positions of less authority and are held to lower standards of accountability—questions we leave to future research. We also find that CPAs over age 65 and BOA actions are negatively correlated $(r=-0.177, p<0.01)$, suggesting the licenses of older CPAs may systematically lapse without penalty. We also find that CPAs associated with larger accounting firms tend to receive less severe PCAOB sanctions $(r=-0.167$, $p<0.001$ for Big 4 firms, and $r=-0.218, p<0.001$ for all annually inspected firms). Perhaps they are viewed as part of a large team such that responsibility for errors is not solely their own. Or, perhaps smaller auditors lack the ability to properly manage audits. Unlike their annually inspected counterparts, during the first few years following the initiation of PCAOB inspections, negative inspection reports of smaller, triennially inspected auditors were associated with both voluntary and involuntary client losses (Daugherty et al. 2011). Another possibility is that larger firms have more resources to hire attorneys with experience practicing before the PCAOB.

To evaluate the sensitivity of our results, we perform several robustness tests using alternative measures of $B O A$
Action and Red BOA, including other potentially highly correlated variables, and excluding certain BOA actions. ${ }^{20}$

In the extreme, red BOAs may chose to ignore any recommendation by a Federal-level regulator, like the PCAOB. Of the 78 "no actions" included in our sample, 56 ( 72 percent) are in red states. To consider the possibility that our results are dependent upon our severity difference scale, we estimate a binary logistic equation with an alternative measure of BOA Action, an indicator variable equal to one if the BOA did not act, otherwise equal to zero. Results are confirmatory of our main tests, the coefficient on Red BOA is negative and statistically significant $(p<0.001)$ and the coefficients on \#CPAs, \#Issuers, Lag, and Non-resident CPA each retains their direction and significance.

Since newly elected governors with different party affiliations may not change all the appointees of prior governors, especially given the voluntary nature of the work, BOAs may include holdover members. Investigations may begin under one political regime and end under another. Of our $234 \mathrm{BOA}$ actions, 16 (seven percent) are associated with BOA actions in 1 year, where the party of the governor was different in the prior year. To determine what, if any, impact this has on the study's results, we estimate the study's equation with the political party in the year prior to the BOA action. In other words, if the governor in the year prior to the BOA action was Blue, Red BOA would be equal to zero in the reestimated equation. Doing this reduces the significance of the coefficient on Red BOA from $p<0.001$ to $p=0.01$, but the direction and significance of the coefficients on the other independent variables are unchanged.

Although they comprise only 12 percent of the total BOA actions, it may be that broker-dealer auditors new to the PCAOB's inspection process beginning in 2013 impact the study's results. Perhaps BOAs decided to systematically go easier on broker-dealer auditors at least for the first few years of being under the supervision of the PCAOB. To evaluate this impact, we include an indicator variable equal to one if the PCAOB sanction relates to the audit of a broker-dealer, otherwise equal to zero $(B D)$. As presented in Table 6, Column B, results are unchanged. The coefficient on the brokerdealer variable is insignificant, while the coefficient Red $B O A$

\footnotetext{
${ }^{20}$ Using ordinal logistic regression to estimate the equation does not change the study's results. The coefficient on Red BOA is significant $(p<0.001)$ and the direction and significance of the control variables is unchanged. An alternative form of the equation used to test the study's hypothesis is: Severity Difference $=$ Red $B O A+B O A$ Characteristics + PCAOB Sanction Characteristics + CPA Characteristics, where Severity Difference is a continuous variable intended to measure the difference in severity of the ordered categorization of PCAOB sanctions (Table 4, range 1 to 5) and the ordered categorization of BOA actions (Table 5, range 0 to 5). Estimating this alternative, using either linear or ordinal regression produces equivalent results. The coefficients on Red BOA are significant $(p<0.01)$ and the direction and significance of the other control variables are unchanged.
} 
remains statistically significant $(p<0.001)$, and the direction and significance of the control variables are unchanged.

In some instances, two or more CPAs in a state are associated with the same PCAOB sanction ( $n=43,18$ percent). It is therefore possible that a BOA might intentionally or unintentionally "spread" the penalty among the audit engagement team. As presented in Table 6, Column C, including an indicator variable (2CPAs) for these BOA actions in the regression equation does not impact the direction or significance of the coefficient on Red BOA $(p<0.001)$ or on the control variables.

It may be that our results are driven by BOA actions in the three largest states, New York and California (red and blue during the period of our analyses), and Florida (red during the period of our analyses) $(n=80)$. To evaluate this possibility, we estimate the regression equation excluding BOA actions associated with these states. Results are substantially unchanged. The coefficient on Red BOA remains statistically significant $(p<0.001)$, and the direction and significance of coefficients on control variables included in the equation are unchanged.

By including Lag, the time between the PCAOB sanction and the BOA action, in the regression equation, we consider the impact of the unique nature of matters adjudicated at the state level on the relationship between the severity of PCAOB sanctions and the severity of BOA actions. It is possible that the unique nature of matters adjudicated at the Federal level also impact the study's results $(n=14)$. To evaluate this possibility, we estimate the regression equation excluding these observations. Results are substantially unchanged. The significance and direction of the coefficients on Red BOA and the other control variables are unchanged.

\section{Conclusions}

We examined the entire population of PCAOB sanctions against CPAs from the first imposed in May 2005, through May 2018, and compared the severity of the sanction to the severity of the response of the CPA's BOA(s). The good news is that during this 13-year period, only 165 CPAs were sanctioned-a small fraction of the CPAs performing issuer-audits. This suggests that the overall quality of auditing services is good. It also implies that to get on the list of sanctioned CPAs, the CPA likely did something particularly egregious, at least as perceived by the PCAOB. That said, we also find that of the sanctioned CPAs, approximately onethird were not punished by their BOA and overall, BOAs punished CPAs less severely than did the PCAOB. This result may reflect the difference between more prosecutoriallike verdicts of the PCAOB and more trial-by-jury-like verdicts of BOAs. ${ }^{21}$ A current BOA member offered that when

${ }^{21}$ Bazelon (2019) describes process and outcome differences in prosecutorial and trial-by-jury actions.
CPAs have already been sanctioned by the PCAOB, BOAs may be reluctant "piling on" penalties-particularly when the state is where the CPA holds a "secondary" license.

Consistent with our hypothesis, we find the severity of BOA actions is influenced by political regime. Controlling for the severity of PCAOB sanctions, BOA characteristics, PCAOB sanction characteristics, and CPA characteristics, BOAs under Republican regimes respond less aggressively to PCAOB sanctions than do BOAs under Democrat regimes. These results are robust using alternative measures of the dependent variable and independent variable of interest, testing for other potentially highly correlated variables, and removing potentially influential observations. As states' political regimes have become increasingly stable over the last several decades, our results may grow even stronger over time. We believe these findings can be generalized to countries outside of the US who have similar two-system political parties and two-tiered regulation of public accountants.

If CPAs are punished less severely than they should be (a normative question beyond the scope of our study), companies may be mis- or underserved by their accountants and investors may suffer more losses than they otherwise might. On the other hand, overly aggressive punishment may stifle economic growth. While differences between states are not problematic per se, they can have public policy implications at both the Federal and state level. For example, should the licensing and regulation of CPAs be delegated to states? If there is value in consistency, perhaps licensing should be by NASBA instead of state BOAs.

According to CPAmobility.org, a webpage sponsored by NASBA and the AICPA, most states have passed legislation allowing a CPA in good standing to practice in another state with substantially equivalent licensing requirements without having to be licensed in that other state. As most states have substantially equivalent licensing requirements, this initiative makes the practice of accounting simpler in terms of licensing and registration. It may, however, complicate enforcement. The Uniform Accountancy Act is silent on how enforcement is to be handled.

As noted, beyond generalized red-state, blue-state differences in enforcement, we find that CPAs holding more than one license are less severely punished by BOAs in states where they do not reside-irrespective of the political regime. In 48 percent of these dual-state licensing matters, BOAs took no action against non-resident CPAs. Although beyond the scope of this research, it may be worthy of policy makers to consider whether BOAs enforce the appropriate level of action for non-resident CPAs. Some states have more staff and/or fewer licensed CPAs and can therefore devote more resources to enforcement activities. If enforcement is not reasonably consistent among BOAs because of the political regime or other differences, regulators may be unwilling to delegate responsibility for enforcement to another state's BOA. 
As far as we know, our is one of the first studies to examine the impact of political regime on the regulation of professionals. States regulate insurers, nursing homes, veterinarians, engineers, architects, real estate agents, and construction contractors, among others. If our conclusions about the operations of state agencies being influenced by political regime generalize beyond accounting contexts, it may be that consumers' insurance losses are greater in red states as a result of less severe enforcement of insurance companies-an idea consistent with the report of Devlin (2002) concerning no-fault auto insurance; or patient mortality rates may be greater in red states as a result of reduced physician or patient care facility monitoring.

A few other observations with potential public policy implications are noteworthy. First, some states seem to have more than their fair share of CPAs sanctioned by the PCAOB. Florida's 23 sanctions put it ahead, size-wise, of much larger states (e.g., New York, California). Utah's 14 sanctions are also disproportionate to its size. Despite being the 6th largest state in terms of the number of licensed CPAs, and 10th largest state in terms of issuers, Ohio's two sanctions put it behind many smaller states. More-directly comparing Florida and Ohio, we are unable to identify any meaningful differences in the policies and practices of their BOAs. Both have nine members appointed by the governor, designated disciplinary committees, and 150 credit hour requirements for licensure. Ohio requires taking a professional standards course (describes by other states as "ethics") prior to certification and triennially thereafter, while Florida requires passing a professional standards course for bi-annual recertification. Florida requires double the number of continuing education hours; Ohio requires $20 \mathrm{~h}$ annually, while Florida requires $80 \mathrm{~h}$ every 2 years. This lack of directionally consistent systematic differences in policies and practices leads us to conclude the difference in PCAOB sanctions may be related to population migration patternsparticularly of retired CPAs.

Before the establishment of the PCAOB, CPAs were largely self-regulated. The SEC's Practice Section required that issuer-auditors participate in the AICPA's peer review program. Since the SEC Practice Section was dissolved when the PCAOB was formed, most states now require a peer review which most CPAs facilitate through the AICPA. The peer review program differs from the PCAOB's inspection program in several ways. Most importantly, in the peer review program, reviewers are other CPAs-not regulators, and results are not made public. The PCAOB and BOAs include CPA representatives, but unlike the AICPA, they are not comprised solely of CPAs. State BOAs differ in their representation of non-CPAs. Future research may explore how BOA member representation affects the severity of sanctions against CPAs as a way of examining the costs and benefits of self-regulation at the state level.
Acknowledgements We are grateful to Colleen Boland, Dana Hermanson, Robert Knechel, Dennis O'Reilly, Alan Reinstein, workshop attendees at Florida Atlantic University, and four anonymous current or recent-past members of two different state boards of accountancy for their thoughtful comments and suggestions.

\section{Compliance with Ethical Standards}

Conflict of interest There are no known conflicts of interest associated with this manuscript.

\section{References}

Abernathy, J. L., Barnes, M., \& Stefaniak, C. (2013). A summary of 10 years of PCAOB research: What have we learned? Journal of Accounting Literature, 32, 30-60.

Bazelon, E. (2019). Charged. New York: Random House.

Bazerman, M. H. (2017). Judgment and decision making. In: R. Biswas-Diener, E. Diener (Eds) Noba textbook series: Psychology, DEF, Champaign, IL.

Beck, M., Hogan, C. E., \& Imdieke, A. (2018). An analysis of the effectiveness and consequences of PCAOB disciplinary actions for auditors and their clients. Working paper.

Black, D. (1948). On the rationale of group decision-making. Journal of the Political Economy, 56(1), 23-34.

Boland, C., Brown, V., \& Dickins, D. (2020). Standard-setting in auditing: Insights from PCAOB inspections. Journal of Accounting \& Public Policy. https://doi.org/10.1016/j.jaccpubpol.2020.106756.

Burton, H., Daugherty, B., Dickins, D., \& Schisler, D. (2016). Dominant personality types in public accounting: Selection bias or indoctrination? Accounting Education: An International Journal, 25(2), 167-184.

California Board of Accountancy (CBA). (2010). CBA meeting agenda (May 12-13). https://www.dca.ca.gov/cba/communications-andoutreach/meetings/materials/2010/mat0510cba.pdf.

Cialdini, R. B., \& Goldstein, N. J. (2004). Party affiliation, partisanship, and political beliefs: A field experiment. Annual Review of Psychology, 55, 591-621.

Coates, J. C. (2007). The goals and promise of the Sarbanes-Oxley Act. The Journal of Economic Perspectives, 21(1), 91-116.

Cohen, A., \& Yang, C. S. (2019). Judicial politics and sentencing decisions. American Economic Journal: Economic Policy, 11(1), 160-191.

Daugherty, B., Dickins, D., \& Tervo, W. (2011). Negative PCAOB inspections of triennially inspected auditors and involuntary and voluntary client losses. International Journal of Auditing, 15(3), $1-16$.

Devlin, R. A. (2002). Determinants of no-fault insurance measures. Journal of Risk and Insurance, 69(4), 555-576.

DiMaggio, P. J., \& Powell, W. W. (1983). The iron cage revisited: Institutional isomorphism and collective rationality in organizational fields. American Sociological Review, 48, 147-160.

Dustin, D. (2012). Purpose and role of State Boards of Accountancy. https://nasba.org/features/the-purpose-and-role-of-state-board s-of-accountancy/.

Elrod, A., Karadas, S., \& Theyson, K. C. (2018). The effect of gubernatorial political parties on monitoring and enforcement of federal environmental regulation: Evidence from the Clean Water Act. Environmental Economics and Policy Studies, 21, 1-32.

Gelman, A. (2009). Red state, blue state, rich state, poor state: Why Americans vote the way they do. Princeton, NJ: Princeton University Press. 
Gerber, A. S., Green, D. P., \& Larimer, C. W. (2008). Party affiliation, partisanship, and political beliefs: A field experiment. American Political Science Review, 102, 33-48.

Gilman, D. J. (2011). Physician licensure and telemedicine: Some competitive issues raised by the prospect of practicing globally while regulating locally. Journal of Healthcare Law \& Policy, 14(1), 87-118

Graham, M. H., \& Svolik, M. W. (2020). Democracy in America? Partisanship, polarization, and the robustness of support for democracy in the United States. American Political Science Review, 114(2), 392-409.

Graham, Jr., R. C. (2014). The complaints process and violations at the Oregon Board of Accountancy. The Accountant (May). https:// www.orcpa.org/news-resources/the-accountant-magazine.

Greene, S. (2004). Social identity theory and party identification. Social Science Quarterly, 85(1), 136-153.

Helland, E. (1998). The enforcement of pollution control laws: inspections, violations, and self-reporting. Review of Economics \& Statistics, 80(1), 141-153.

Herron, T. L., \& Gilbertson, D. L. (2011). When auditors fail to audit: Themes from PCAOB enforcements. CPA Journal, 81(5), 50-57.

Janis, I. L. (1982). Groupthink: Psychological studies of policy decisions and fiascoes. Boston, MA: Houghton Mifflin.

Juric, D., O'Connell, B., Rankin, M., \& Birt, J. (2018). Determinants of the severity of legal and employment consequences for CPAs named in SEC accounting and auditing enforcement releases. Journal of Business Ethics, 147(3), 545-563.

Kahneman, D., \& Klein, G. (2009). Conditions for intuitive expertise: A failure to disagree. American Psychologist, 64(6), 515-526.

Klebnikov, S. (2020). Here are the 9 State governors who have refused to issue stay-at-home orders. Forbes (April 4). https://www. forbes.com/sites/sergeiklebnikov/2020/04/04/here-are-the-9state-governors-who-have-refused-to-issue-stay-at-home-order s/\#e1fa3aa4eebf.

Krom, C. L. (2016). Disciplinary actions by State boards of accountancy 2008-2014: Causes and outcomes. Accounting and the Public Interest, 16(1), 1-27.

Krom, C. L. (2019). Disciplinary actions by State professional licensing boards: Are they fair? Journal of Business Ethics, 158(2), $567-583$.

Leigh, A. (2008). Estimating the impact of gubernatorial partisanship on policy settings and economic outcomes: A regression discontinuity approach. European Journal of Political Economy, 24(1), 256-268.

Love, V. J. (2016). Parallel proceedings in accounting litigation: The position(s) taken by the self-regulatory organizations and State Boards of Accountancy. The Practical Lawyer (April), 35-43.

Lowry, R. C. (2013). Public welfare spending and private social services in U.S. States. State Politics and Policy Quarterly, 13(1), $3-25$.

Marquis, C., \& Tilcsik, A. (2016). Institutional equivalence: How industry and community peers influence corporate philanthropy. Organization Science, 27(5), 1325-1341.
Meier, K. J. (1991). The politics of insurance regulation. Journal of Risk and Insurance, 58(4), 700-713.

Newkirk, II., V. R. (2017). How redistricting became a technological arms race. The Atlantic (October 28). https://www.theatlanti c.com/politics/archive/2017/10/gerrymandering-technology -redmap-2020/543888/.

Organisation for Economic Co-operation and Development (OECD). (2000). Reducing the risk of policy failure: Challenges for regulatory compliance. https://www.oecd.org/gov/regulatory-polic y/46466287.pdf.

Rampell, C. (2018). Is the GOP the law and order party? Not so much. Washington Post (December 10). https://www.washington post.com/opinions/is-the-gop-the-law-and-order-party-not-somuch/2018/12/10/b646336e-fcc0-11e8-ad40-cdfd0e0dd65a_story .html?noredirect=on\&utm_term $=$.fcecb11b8246.

Schloemer, P. G., \& Schloemer, M. S. (1997). The personality types and preferences of CPA firm professionals: An analysis of changes in the profession. Accounting Horizons, 4, 24-39.

Scott, W. R. (2008). Institutions and organizations: Ideas and interests (3rd ed.). Thousand Oaks, CA: Sage Publications.

Seib, G. (2012). No sign of voter polarization warning. Wall Street Journal (July 10), A4.

Seib, G. (2019). How the U.S. became a nation divided. Wall Street Journal (December 17). https://www.wsj.com/articles/how-theu-s-became-a-nation-divided-11576630802.

Shackleton, V. (1980). The accountant stereotype: Myth or reality? Accountancy, 9, 122-123.

Short, J. R. (2018). Four reasons gerrymandering is getting worse. The Conversation (October 29). http://theconversation.com/4-reasonsgerrymandering-is-getting-worse-105182.

Spencer, A. W., Usrey, S. C., \& Webb, T. Z. (2015). The disclosure of CPA disciplinary action. A state-by-state overview. CPA Journal (March), 60-63.

Sunstein, C. R., Schkade, D., Ellman, L. M., \& Sawicki, A. (2006). Are judges political? An empirical analysis of the federal judiciary. Washington, D.C.: Brookings Institution Press.

Tajfel, H., \& Turner, J. C. (1979). An integrative theory of intergroup conflict. In W. G. Austin \& S. Worchel (Eds.), The social psychology of intergroup relations (pp. 33-47). Brooks/Cole: Monterey, CA.

Tajfel, H., \& Turner, J. C. (1986). The social identity theory of intergroup behaviour. In S. Worchel \& W. G. Austin (Eds.), Psychology of intergroup relations (pp. 7-24). Chicago, IL: Nelson-Hall.

Wittman, D. (1983). Candidates motivation: A synthesis of alternatives. American Political Science Review, 77, 142-157.

Publisher's Note Springer Nature remains neutral with regard to jurisdictional claims in published maps and institutional affiliations. 